\title{
ARTICLE
}

\section{Aggression and dominance in matched groups of subadult Icelandic horses (Equus caballus)}

\author{
Hilde Vervaecke $\cdot$ Jeroen M. G. Stevens • \\ Harold Vandemoortele · Hrefna Sigurjónsdóttir · \\ Han De Vries
}

Received: 15 April 2006/ Accepted: 7 August 2006

(C) Japan Ethological Society and Springer 2006

\begin{abstract}
We studied sex differences in the nature of aggression and dominance behaviour in two newly formed groups of 1-year-old Icelandic horses. One herd contained nine geldings, the other nine mares. The groups were matched with regard to dominancedetermining traits such as age, weaning age, composition of native herd, social experience, genetic origin, body condition and maternal dominance status. Highranking individuals of both sexes were more aggressive, high-ranking males were older, and high-ranking females had a better body condition. Frequencies of
\end{abstract}

H. Vervaecke

KAHO Sint-Lieven, University of Leuven, Ethology Group,

Hospitaalstraat 23, 9100 Sint-Niklaas, Belgium

\section{J. M. G. Stevens}

Royal Zoological Society of Antwerp,

Centre for Research and Conservation,

K. Astridplein 26, 2018 Antwerp, Belgium

\section{J. M. G. Stevens}

Department of Biology, University of Antwerp,

Universiteitsplein 1, 2610 Wilrijk, Belgium

H. Vandemoortele $\cdot$ H. Sigurjónsdóttir

Iceland University of Education, Stakkahlíð, 105,

Reykjavík, Iceland

\section{H. De Vries}

Department of Behavioural Biology,

Padualaan 14, Postbus 80.086, 3508 TB Utrecht,

The Netherlands

H. Vervaecke $(\bowtie)$

Domaine de Bois St. Jean 7, 6982 Samrée,

Belgium

e-mail: bizonobo@skynet.be aggressions were similar in both groups. The mares reacted significantly more by showing submission upon an aggression rather than by not responding or by escalating the aggression. For the geldings, this difference was not observed due to a lower tendency to submit. A linear dominance hierarchy was found in both groups. David's scores provided additional information regarding cardinal rank distances and were used to calculate steepness of hierarchies. The female hierarchy was somewhat steeper compared to the male hierarchy, suggesting somewhat lower despotism among males. This was mainly a consequence of the lower unidirectionality in male submission. Male contests occurred predominantly between dyads at top and mid positions, suggesting a low degree of acceptance of the hierarchy.

Keywords Equus - Dominance - Aggression · Hierarchy $\cdot$ Steepness

\section{Introduction}

The study of dominance hierarchies has received considerable interest in behavioural studies, mainly because of the relation between dominance and fitness (Ellis 1995). Because male and female fitness in polygynous species is influenced by different resources, competitive regimes can also be expected to differ between the sexes. Male fitness is mainly influenced by the number of fertilizations, and to a far lesser extent by food resources (Bateman 1948; Trivers 1972). Because fertilizations cannot be shared, competitive regimes between males are intense and aggressive (Smuts and Smuts 1993). 
Female fitness, on the other hand, is mainly influenced by distribution of food resources and not so much by competition for partners. In the case of grazing herbivores, it is often assumed there is very little "interference feeding competition" between females, as food resource quality is expected to show little variation (Van Schaik 1989). Generally, it is indeed in the female sex that aggression is less forceful (Smuts and Smuts 1993; Floody 1983). This should result in measurable differences in the quality of dominance relations. While male dominance relationships are expected to be characterised by fierce competition, female dominance relationships are expected to be more relaxed.

Quality of a hierarchy can apply to characteristics of the ordinal as well as cardinal dominance rank. The former provides information on the linearity of the dominance order and the consistency of the direction of the interactions among dyads. The latter quantifies rank distances between individuals, based upon their relative probability of winning or losing dominance interactions (de Vries 1998) and can be used to calculate a measure of the steepness of the hierarchy (De Vries et al. 2005). Dominance relations that are consistent, transitive and stable result in a strongly linear and steep, i.e. despotic, hierarchy (sensu Van Schaik 1989).

The study of the structure and quality of dominance relations is complicated by many methodological issues, since the formation and dynamics of dominance relations are influenced by several rank-determining factors, such as age and weight (Drews 1993). Evaluations of the differences between male and female hierarchies should attempt to control for these factors.

In horses (Equus caballus), several dominancedetermining factors have been proposed. Weight relates positively with rank (Clutton-Brock et al. 1976; Berger 1977; Houpt and Wolski 1980) but this was contradicted by Houpt and Keiper (1982). Height correlates positively with rank (Rutberg and Greenberg 1990), and increasing age has been related to higher rank in several studies (Keiper and Sambraus 1986; Keiper 1998; Rutberg and Greenberg 1990; Van Dierendonck et al. 1995; Sigurjónsdóttir et al. 2003). In a herd where the oldest mares were the smallest, the age factor was more important (Van Dierendonck et al. 1995). Castration is known to decrease male aggressive behaviour (Anisko et al. 1973) and general aggressiveness (Dabbs et al. 1995; Mazur and Booth 1998) or to prevent its development (Whitsett 1975) especially if performed early (Motelico-Heino et al. 1993), before puberty and before aggressive behavior patterns are learned. For geldings, the previous socio-sexual experience was found to be a more important dominance-determining factor than the age of castration (Van Dierendonck et al. 1995). Further, genetic disposition plays a role in dominance behaviour since maternal aggressiveness correlated well with aggressiveness in the offspring (Van Dierendonck et al. 1995; for daughters: Houpt et al. 1978; but see Keiper and Sambraus 1986). Maternal reproductive parity related to increase in rank (Keiper and Sambraus 1986), and the same was found for time of residence in the herd (Van Dierendonck et al. 1995).

In this study we investigated sex differences in aggression, linearity and steepness of the hierarchy in two newly established all-male and all-female groups of young Icelandic horses. The groups were matched to obtain two homogeneous groups with respect to several dominance-determining factors other than sex, i.e. age, weaning age, composition of native herd, social experience, genetic disposition, maternal status and body condition.

\section{Materials and methods}

\section{Group composition}

Two groups of Icelandic horses (Equus caballus) were formed for the purpose of this study: one group contained nine mares, the other nine geldings. All individuals were approximately the same age (varying between 56 and 60 weeks), were approximately the same height (1.09-1.19 m), and had been weaned at 8 months of age. None of the individuals had been in contact prior to group formation, but all individuals of both groups had lived in herds with similar compositions so that all had had the potential for similar exposure to social contacts. We controlled, at least to some extent, for genetic differences in the expression of dominance behaviour, by selecting paternal half brothers and sisters for four of the nine individuals in each herd. To control for influence of differences in previous maternal experience, each of the mothers of the study animals had had at least two foals. An equal number of these mothers in both the male and female groups belonged to the top, mid or low dominance rank class (based on the owners' judgment) so as to control for effects of maternal rank. The group composition was similar with respect to body condition of the study animals, expressed as a score of one to three (body volume in relation to height, hair condition) as estimated by a professional horse rater. Within each of the groups, the animals with a good (four males, five 
females), medium (three males, three females) or bad body condition (two males, one female) were about equal. The males had had no previous sexual experience and had been castrated 1 month prior to the observation period.

Study site

Observations were carried out on the farm "Bessastadir" on Heggstadanes in northwestern Iceland. Both groups were kept on separate meadows with similar vegetation, separated by $2 \mathrm{~km}$. Temperature varied between -2 and $15^{\circ} \mathrm{C}$. Ample water and grass were available. The female herd had 100 ha available, the males 30 ha. Since the spatial group structures of the male and female groups were the same (i.e. both formed one cohesive group without subgroups or satellite animals), we think that the meadow size difference did not affect the rate of aggressive interactions.

\section{Behavioural observations}

Both groups were formed on 9 July 2002. Behavioural observations were carried out between 12 July and 22 august. Each group was studied for a total of $100 \mathrm{~h} \mathrm{(3 \textrm {h }}$ per group per dayc). Observations covered all hours except the brief periods of darkness (10-60 $\mathrm{min} / 24 \mathrm{~h}$ ), and care was taken to cover all hour ranges in both herds. The horses were followed on foot from a distance of 5-30 m. All occurrences of aggressive and submissive interactions were scored by ad libitum sampling (Altmann 1974; Lehner 1996).

\section{Ethogram}

\section{Aggressive behaviours}

- Ears laid back: Head is turned in the direction of the receiver and extended with ears pressed caudally against the head (McDonnell and Haviland 1995).

- Bite threat: Head is thrown in direction of receiver, ears are flattened against the neck, teeth are bare or a bite movement is made without contact.

- Bite: Threat bite with contact; actor does not move more than two strides towards receiver.

- Kick threat: Ears flat against neck, rear is turned to receiver and one of the hind legs is lifted off the ground.

- Kick: Kick threat and the hind leg is kicked towards receiver, eventually with contact.

- Attack: Ears laid back, bite threat and kick threat, but action is more energetic, neck is more extended, and the actor moves more than two strides in the direction of the receiver.

- Chase: Following and chasing other individual, often in gallop, with ears laid back. A longer distance is covered, and it is less explosive than an attack.

- Fight: Contact aggression with repeated bites, kicks and high intensity.

- Shouldering: Pushing the receiver aside with the shoulder.

- Push back: Pushing the receiver away by approaching backwards or by pushing the receiver with the hindquarters.

- Strike: Kicking with the foreleg with or without contact.

- Threat approach: Approach the receiver with ears backward (not flat against the neck). Head is not extended as far as in ears laid back (analogous to herding, McDonnell and Haviland 1995).

\section{Severe and moderate aggression}

In the analysis, a distinction is made between severe and moderate aggression. Moderate aggression includes all aggression without contact, i.e. ears laid back, threat bite, kick threat, threat approach, as well as moderate contact aggressions such as shouldering or push back. Severe aggressions include all other aggressive physical contact-bite, kick, fight, attack-and chases. Playful aggressive interactions-characterised by sidewise or frontal position of the ears-were distinguished from aggressive interactions and are not analysed here.

\section{Submissive behaviours}

- Yield: Turning the head away or moving away a maximum of two strides. Neck is kept low, ears backward, but not as expressive as in ears laid back.

- Retreat: Moving away from other individual after interaction.

- Flee: Moving away in a fast walk, up to a fast gallop. Ears are often backward.

\section{Submissive versus non-submissive interactions}

- Submissive interactions: Interactions in which the individual reacted with submissive behaviour following an aggression.

- Non-submissive interaction: Interactions in which the individual ignored the received aggressive behaviour, either by showing no reaction or by showing a counter-aggression, resulting in escalated conflict. 
Scoring of interactions

A new interaction was scored after an interruption of more than $5 \mathrm{~s}$. An uninterrupted chain of interactions was divided into distinct interactions, e.g. A threat bite $\mathrm{B}, \mathrm{B}$ threat bite $\mathrm{A}=\mathrm{A}$ threat bite $\mathrm{B}, \mathrm{B}$ no submission, B threat bite A....

Rank-order analysis

For rank-order analysis, all possible agonistic behaviours followed by a submissive behaviour were used, i.e. all behaviours eliciting either yield, retreat or flee as reactions. The dominance matrix was analysed with MatMan (version Mfw 1.0; earlier version described in de Vries et al. 1993) and reordered to find an order most consistent with a linear hierarchy according to the I\&SI method, which minimises the number of inconsistencies (I) and the strength of inconsistencies (SI) (De Vries 1998). Dyads, which thereafter still showed a direction of interactions that did not fit the linear order, were "inconsistent dyads".

The index of linearity $h$ (Appleby 1983) was calculated and tested for significance by means of a randomization test in MatMan (de Vries 1995). In the linear rank order, the top individual is assigned rank one, the lowest ranking individual rank 9. The directional consistency index (DC) gives the frequency with which the behaviour occurred in its more frequent direction relative to the total number of times the behaviour occurred (Van Hooff and Wensing 1987). As another descriptive measure, the number of one-way relationships was counted, i.e. the number of dyads in which the behaviour is shown in one direction only, irrespective of the frequency of interaction within the dyads. In two-way relationships, dyadic dominance interactions occurred at least once in both directions (from A to B and from B to A). Circular triads contain an intransitive relationship among $\mathrm{A}, \mathrm{B}$ and $\mathrm{C}$, and can be considered to be an indication of instability (Wiepkema and Van Hooff 1977).

We calculated adjusted, normalised David's scores (David 1987; Gammell et al. 2003; De Vries 1998; Appendix 2 in De Vries et al. 2006) as a measure of dominance that takes the relative strength of the opponents into account. These are then used to calculate a measure of steepness, which varies from 0 to 1 , in which 0 is considered indicative of an egalitarian dominance hierarchy, with small rank distances, while a slope of 1 indicates a strictly despotic dominance hierarchy with large rank differences (sensu Van Schaik 1989). Finally, the difference was tested among the 36 dyadic dominance indici corrected for chance $\left[D_{i j}=\left(S_{i j}+0.5\right) /\left(n_{i j}+1\right)\right]$ for males and females by means of a Mann-Whitney $U$ test, where $S_{i j}$ is the number of times that $i$ defeats $j$ and $n_{i j}$ is the total number of interactions between $i$ and $j$.

Other analyses

Kolmogorov-Smirnov tests were applied to evaluate normality or non-normality of the data prior to applying the appropriate statistical tests, performed with SPSS software. $P$ values for significance were set at 0.05 . All tests were two-tailed except when indicated differently.

\section{Results}

Severity of aggression

\section{Distribution of aggressions}

Figure 1 shows the distribution of aggressive acts in both sex groups per individual. There was no significant difference between the sexes in mean number of aggressive acts $(t=0.477, d f=16, P=0.640)$. There was no significant difference in mean number of severe aggressions $(t=-0.512, d f=16, P=0.616)$ or moderate aggressions $(t=0.987, d f=16, P=0.338)$. Both sex groups showed no significant difference in total individual number of aggressions followed by submission ( $t$-test:

Total frequency of aggressions

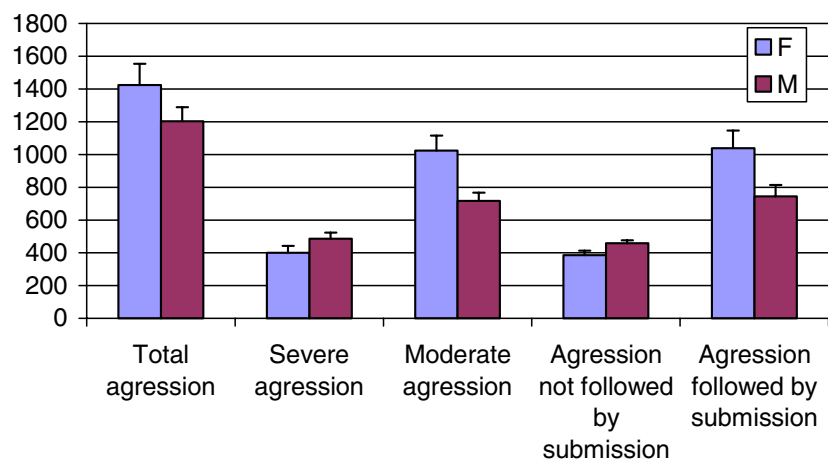

Fig. 1 Total frequency of aggressive acts (total aggression, moderate versus severe aggression, aggression not followed by submission versus aggression followed by submission) in both sex groups 
$t=0.767, d f=16, P=0.454)$ nor in number of aggressions that were not followed by submission $(t=-0.732, d f=16$, $P=0.475)$. Mares showed significantly fewer severe aggressions than moderate aggressions (paired $t$-test: $3.570, d f=8, P=0.007)$. The same was true for the males (paired $t$-test: $3.529, d f=8, P=0.008$ ).

\section{Distribution of reactions upon aggression}

The mares showed significantly more aggressions followed by a submission rather than aggressions that were not followed by submission $(t=2.473, d f=8$, $P=0.039)$. For the males, there was no significant difference in number of aggressions that were followed by submission and aggressions that were not followed by submission $(t=1.746, d f=8, P=0.119)$.

Linearity of dominance hierarchies

\section{Dominance hierarchy}

For both the female and male groups, a linear hierarchy could be constructed based on the frequency of aggressions that were followed by submission (Table 1), and animals could be ranked accordingly (Tables 2,3). There were no unknown relations in either of the groups. Linearity of the hierarchies was high (0.97 and 0.93 for females and males respectively) and highly significant. Regarding the direction of submission, the directional consistency index in females was somewhat higher than in males (0.78 and 0.60 , respectively). There was one inconsistent dyad in the female group, and two inconsistent dyads in the male group.

As an additional measure, normalised David's scores, based on the dyadic dominance index (NDSDDI values) were calculated (Table 4). These values correlated strongly with the ranks based on the I\&SI

Table 1 Results of rank-order analysis based upon matrices 1 and 2

\begin{tabular}{lll}
\hline & Females & Males \\
\hline$N$ & 1,039 & 745 \\
$h^{\prime}$ & 0.97 & 0.93 \\
Significance & $P<0.0001$ & $P<0.0001$ \\
DC & 0.77 & 0.60 \\
Unknown relationships & 0 & 0 \\
One-way relationships & 6 & 8 \\
Two-way relationships & 30 & 28 \\
Tied relationships & 0 & 0 \\
Number of circular triads & 1 & 2 \\
Inconsistent dyads & MU-VB & TOR-ZG, MU-BO \\
\hline
\end{tabular}

method: $r_{\mathrm{s} \text { females }}=-0.83, P=0.002, n=9 ; r_{\mathrm{s} \text { males }}=-0.983$, $P<0.0001, n=9$; two-tailed values).

Steepness of dominance hierarchy

We used the NDS-DDI values to calculate steepness of the dominance hierarchies (Figs. 2, 3). In both

Table 2 Reordered dominance matrix of female aggressions that were followed by submission

\begin{tabular}{lllllllllll}
\hline & V & VS & B & FJ & PR & VB & TOR & MU & ZV & Total \\
\hline V & 0 & 58 & 50 & 61 & 32 & 37 & 29 & 39 & 25 & 331 \\
VS & 8 & 0 & 22 & 22 & 9 & 27 & 20 & 10 & 48 & 166 \\
B & 3 & 3 & 0 & 19 & 29 & 12 & 13 & 19 & 8 & 106 \\
FJ & 5 & 8 & 9 & 0 & 33 & 38 & 35 & 32 & 57 & 217 \\
PR & 4 & 7 & 9 & 1 & 0 & 28 & 26 & 16 & 23 & 114 \\
VB & 4 & 3 & 0 & 0 & 6 & 0 & 7 & $6^{\text {a }}$ & 12 & 38 \\
TOR & 2 & 0 & 4 & 1 & 4 & 4 & 0 & 5 & 3 & 23 \\
MU & 0 & 2 & 1 & 1 & 5 & $8^{\text {a }}$ & 3 & 0 & 10 & 30 \\
ZV & 3 & 1 & 3 & 0 & 0 & 4 & 1 & 2 & 0 & 14 \\
Total & 29 & 82 & 98 & 105 & 118 & 158 & 134 & 129 & 186 & 1,039 \\
\hline
\end{tabular}

${ }^{a}$ Frequency of aggression in inconsistent dyads

Table 3 Reordered dominance matrix of male aggressions that were followed by submission

\begin{tabular}{lllllllllll}
\hline & ZG & PR & TOR & ZR & MU & BO & V & ZH & VB & Total \\
\hline ZG & 0 & 24 & $10^{\text {a }}$ & 10 & 24 & 17 & 16 & 5 & 7 & 113 \\
PR & 11 & 0 & 50 & 31 & 32 & 30 & 26 & 21 & 25 & 226 \\
TOR & $14^{\mathrm{a}}$ & 9 & 0 & 23 & 28 & 21 & 17 & 13 & 12 & 137 \\
ZR & 4 & 15 & 22 & 0 & 8 & 15 & 8 & 14 & 24 & 110 \\
MU & 1 & 4 & 2 & 5 & 0 & 14 & $4^{\mathrm{a}}$ & 6 & 12 & 48 \\
BO & 0 & 0 & 7 & 1 & 6 & 0 & 11 & 2 & 15 & 42 \\
V & 2 & 3 & 8 & 2 & $6^{\mathrm{a}}$ & 3 & 0 & 5 & 7 & 36 \\
ZH & 0 & 0 & 3 & 1 & 4 & 0 & 2 & 0 & 4 & 14 \\
VB & 0 & 0 & 0 & 1 & 6 & 4 & 5 & 3 & 0 & 19 \\
Total & 32 & 55 & 102 & 74 & 114 & 104 & 89 & 69 & 106 & 745
\end{tabular}

${ }^{a}$ Frequency of aggression in inconsistent dyads

Table 4 I\&SI ranks and NDS-DDI values for the male and female group

\begin{tabular}{llllll}
\hline $\begin{array}{l}\text { Name of } \\
\text { female }\end{array}$ & $\begin{array}{l}\text { NDS-DDI } \\
\text { female }\end{array}$ & $\begin{array}{l}\text { Rank } \\
\text { female }\end{array}$ & $\begin{array}{l}\text { Name } \\
\text { of male }\end{array}$ & $\begin{array}{l}\text { NDS- } \\
\text { DDI } \\
\text { male }\end{array}$ & $\begin{array}{l}\text { Rank } \\
\text { male }\end{array}$ \\
\hline V & 7.37 & 1 & ZG & 6.64 & 1 \\
VS & 5.99 & 2 & PR & 6.62 & 2 \\
FJ & 5.58 & 4 & TOR & 5.40 & 3 \\
B & 5.03 & 3 & ZR & 5.33 & 4 \\
PR & 4.28 & 5 & BO & 3.06 & 6 \\
MU & 2.28 & 8 & MU & 2.97 & 5 \\
VB & 2.17 & 6 & V & 2.80 & 7 \\
TOR & 2.14 & 7 & ZH & 1.69 & 8 \\
ZV & 1.16 & 9 & VB & 1.48 & 9 \\
\hline
\end{tabular}

The highest-ranking individual is assigned the lowest rank number 


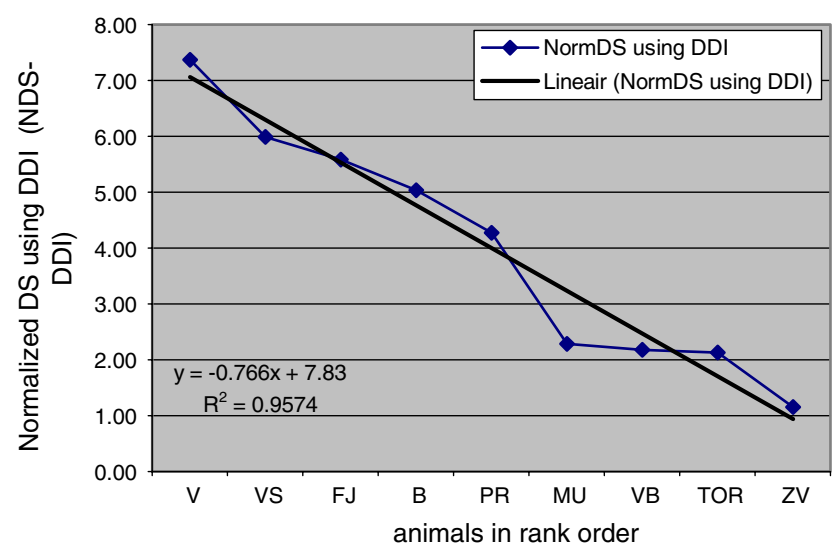

Fig. 2 Steepness of female hierarchy

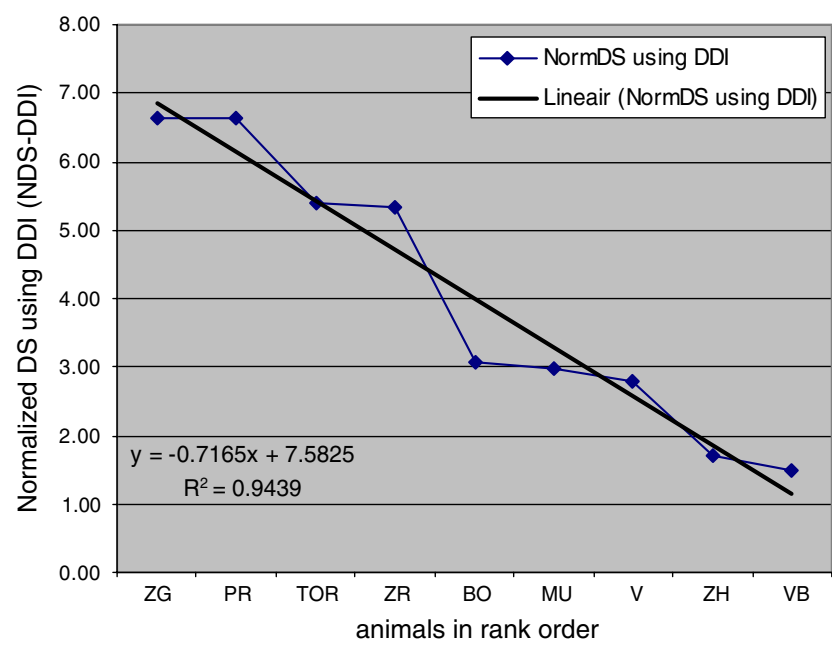

Fig. 3 Steepness of male hierarchy

groups the linear regression line fit well $\left(R_{\text {females }}^{2}=0.96\right.$; $R_{\text {males }}^{2}=0.94$ ). The female hierarchy was somewhat steeper than the male hierarchy slope $_{\text {females }}=0.77$; slope $_{\text {males }}=0.72$ ), indicating that rank distances among females were a bit larger than among males. This is also visible in the graphs: while the rank distances between subsequently ranked females are relatively constant, except for the trio MU-VB-TOR, the rank distances between the males show clusters of pairs or trios of males (ZG-PR, TOR-ZR; BO-MU-V, ZH-VB) between whom the rank distances are small, with larger distances between the pairs or trios. However, the dyadic dominance index corrected for chance, as dyadic measures of steepness, did not differ significantly between males and females (MWU, $P=0.46$ ).
Table 5 Correlates of rank with individual attributes

\begin{tabular}{|c|c|c|c|c|}
\hline & \multicolumn{2}{|l|}{ Males } & \multicolumn{2}{|c|}{ Females } \\
\hline & $r_{\mathrm{s}}$ & $\begin{array}{l}\text { Two- } \\
\text { tailed } P\end{array}$ & $r_{\mathrm{s}}$ & $\begin{array}{l}\text { Two- } \\
\text { tailed } P\end{array}$ \\
\hline Rank-age & -0.64 & 0.06 & -0.48 & 0.19 \\
\hline Rank-weaning age & -0.12 & 0.76 & -0.25 & 0.51 \\
\hline Rank-castration age & -0.49 & 0.18 & - & - \\
\hline Rank-body condition & 0.56 & 0.12 & 0.67 & $0.05^{*}$ \\
\hline Rank-birth order & 0.07 & 0.86 & -0.02 & 0.97 \\
\hline Rank-rank mother & -0.22 & 0.57 & -0.19 & 0.63 \\
\hline Rank-aggressiveness & -0.90 & $0.001^{*}$ & -0.89 & $0.001^{*}$ \\
\hline
\end{tabular}

$* P<0.05$; note that the highest ranking individual was assigned the lowest rank number

Correlates of individual attributes with rank

The correlations of individual attributes with rank are listed in Table 5. In the female group, there was a significant positive correlation between dominance rank and body condition $\left(r_{\mathrm{s}}=0.48, P<0.05\right)$. The individuals with the best body condition were highest in rank. In both groups, aggressiveness decreased with decreasing rank (males: $r_{\mathrm{s}}=-0.90, P<0.001$; females: $\left.r_{\mathrm{s}}=-0.89, P<0.001\right)$. Higher-ranking individuals were more aggressive. Within the male group, there was a trend towards a positive association between age in weeks and dominance rank $\left(r_{\mathrm{s}}=-0.64, P=0.06\right)$. The older males tended to have a higher rank. Other factors [age at weaning, age at male castration, birth order of the individual (previous number of foals of the mother), and rank class of the mother] did not correlate significantly with rank.

\section{Discussion}

It was our aim to study sex differences in the dominance relations in two groups of Icelandic horses of each sex. To control for rank-determining effects of age, height, maternal condition and rank, two matched groups were constructed. Thus although there was variation among individuals within each group, this variation was approximately equal between groups. With regard to the effect of individual factors upon dominance, we found that body condition and dominance correlated significantly in the female herd, in line with findings in other ungulates where a higher agonistic dominance rank relates to better body condition (e.g. Bison bison: Vervaecke et al. 2005; Bos taurus: Reinhardt and Reinhardt 1975; Capra hircus: Barosso et al. 2000), especially in periods of food limitation and in periods in 
which ranks are established or challenged (e.g. B. bison: Lott and Galland 1987). Aggressiveness was also significantly linked with rank in both study groups. It can be hypothesized that more aggressive individuals obtain higher ranks as well as better food access, which in turn affects the body condition of the individual. It should also be considered that aggression is a consequence of rank rather than cause, i.e. the higher the rank, the more you are likely to be challenged and therefore to express more aggression.

We expected that the quality of aggressive relations would differ between males and females, given their different incentives for reproductive competition. Males are thought to experience fierce competition, whereas this should be more relaxed in females. We found however that the different modes of aggression were expressed equally frequently in males as in females. This finding may possibly be due to the fact that the males were castrated, which may have somewhat reduced their aggressive tendencies (Anisko et al. 1973; Dabbs et al. 1995; Mazur and Booth 1998; Whitsett 1975).

Overall, the dominance relations in the male study group were somewhat less rigid, less linear and less steep than the female hierarchy. How can this slightly lower despotism among the males be explained? First, it should be noted that the comparison of the linearity and steepness of dominance hierarchies across the two data sets is methodologically correct given the similar sampling effort and given the fact that in both the male and female groups, the rank relationships among all dyads were known (Galimberti 2003). Thus the observed differences were not due to methodological factors.

It can be argued that the lower index of linearity in males may be a consequence of the fact that the hierarchy is based on a slightly lower number of aggressions than for the females. The probability of reaching a higher linearity would decrease in groups with fewer data points available (Galimberti et al. 2003). The males indeed showed a somewhat-although not significantly-lower number of aggressions followed by submission than the females.

A lower male steepness would be expected if the males showed a higher degree of fierce aggressions since the higher initial dominance of the males (e.g. due to larger body size), single events of victory lead to less differentiation than among the females (Hemelrijk and Gygax 2004). However in this study, males were not "fiercer" in aggression than females. Alternatively, the slightly lower male steepness may be mainly a consequence of their lower unidirectionality in submission, suggesting that the males generally showed a lower degree of acceptance of the hierarchy. Several other observations support this conclusion. First, the rank distances were not only smaller for males than for females but showed a more clustered pattern. The two top males did not show well-differentiated normalised David's scores, nor did the next two individuals. Second, there were slightly more inconsistent male than female dyads, implying that lower ranking males occassionally dared to aggress higher-ranking individuals. These inconsistent dyads occurred at the top and in the middle. Both latter facts suggest ongoing male disputes over the high and mid positions.

It may also be that the males dispute most with the closest ranking individuals. In the females, the normalised David's scores were well differentiated among the top females and the inconsistent female dyad was situated at the lower part of the hierarchy, indicating an acceptation of the five highest ranked individuals. Overall, the males appear less inclined to accept a low dominance rank. This is reflected by the insignificant difference among aggressions followed or not followed by submission. In the females on the other hand, we saw significantly more aggressions that were responded to with submission than not. A similar style difference between the sexes was described for Barbary macaques by Preuschoft et al. (1998), where females were more ready to comply with claimed status asymmetries than males.

From an evolutionary perspective, the lower male tendency to comply with the hierarchy can be explained by the higher male gains of high rank compared to females. Maturing males will fight with other males for access to young females of an existing harem or to become the harem holder of a bachelor female herd (Schilder 1990; Berger 1986; Waring 2003). The top male will have the best chance of displacing his lower ranking competitors and successfully siring offspring (in horses: Feh 1990; in zebra: Schilder and Boer 1987). McDonnell (1992) notes that when a harem becomes available, one of the bachelor band stallions emerges to take the harem with little dispute from other bachelors as though the order of access to a harem is an established aspect of the bachelor band.

Concerning the females, their well-developed linear hierarchy may indicate that females are less likely to pay the costs of escalating conflicts and more likely simply to submit to the aggressive acts of conspecifics. Generally, aggressions among females are known to be less salient than among males (Ellis 1995), except during the periods in which they have foals (Berger 1986, p. 158). The relatively steep female dominance hierarchy, indicative of despotic dominance relationships, may at first sight be surprising given the expected 
low reproductive benefit of competition in females (Trivers, 1972). High steepness is theoretically linked to a high degree of intra-group competition and to a subsequent potential high variance in success (Vehrencamp 1983). Generally, however, female variance in reproductive success is lower than in males (Bateman 1948; Trivers 1972). Nevertheless, Koenig (2002) has suggested that there is significant potential for competition for resources even among female herbivores if only the proximate measures of feeding competition and net energy gain are properly quantified. Apart from feeding competition, competition for social services from other individuals may be an important factor affecting interactions among females (Swedell 2001; Sterck et al. 1997). Therefore the functional importance of female rank should not be underestimated. High ranking captive zebra females were found to produce significantly more foals (Schilder 1990). In other species too, female dominance was linked to subtle but significant fitness pay-offs (e.g. primates: Harcourt 1987; Pan troglodytes: Pusey et al. 1997; Oryctolagus cunniculus; von Holst et al. 2002; B. bison: Vervaecke et al. 2005; Equus burchelli: Pluhacek et al. 2006).

It can be argued that evolutionary explanations do not hold for domesticated animals, which were selected for reduced fear, increased sociability, and reduced anti-predator response (Jensen 2006), factors that may affect the hierarchy formation and group cohesion. Icelandic ponies are rather primitive horses with a late glacial origin (Jansen et al. 2002). Primitive domestic Konik horses that can roam freely form male bands and harems, and male bachelor herds (Markerink 2002), similar to wild Prezwalski horses (Klimov 1988) and to feral horse groups (Berger 1986; Keiper 1986), suggesting a natural adaptive potential in primitive domestic horses.

The artificial group structures of the study may have affected the study results. Female groups as in this study are seldom formed in the wild without a male present, and young male bachelor groups are usually smaller than the nine individuals in this study. In addition, the male bachelor group composition tends to be very flexible (Berger 1986). As a result, the male interactions may have been expressed more strongly and the female interactions were not counteracted by the male dominant behaviour. Wild zebra stallions did not express dominance hierarchies (Klingel 1967), whereas zebra stallions in semi-captivity did, which could be attributed to different observation methods or to differences in feeding competition or density (Schilder 1988). Van Dierendonck et al. (1995) carefully reviewed the studies on hierarchies in wild and feral horses and concluded that both form stable dominance hierarchies. In other words, several aspects of domestic and feral horse behaviour overlap, but the nature of social groups can be very different depending on the individuals comprising them and on an array of group-related factors such as group size, density, stability, and sex ratio. Therefore these results should not be generalised to include all horses. Since each sex in our study was represented by only one group, conclusions with regard to sex-specific traits must be considered with caution.

Acknowledgements We thank Johann B. Magnusson of the Bessastadir ranch in Iceland and all the ranches that allowed the use of their horses in this study. We kindly thank Machteld Van Dierendonck (University of Utrecht) for her assistance. Iceland University of Education supported the research. Harold Van de Moortele set up the study and performed the observations during his training as psychological assistant at the Department of Psychology of the Lessius Institute in Antwerp, Belgium. Hilde Vervaecke was funded by the Fund for Scientific Research Flanders (FWO). Jeroen Stevens was funded by the IWT. The CRC thanks the Flemish Government for financial support. We kindly thank the reviewers for their suggestions.

\section{References}

Altmann SA (1974) Observational study of behaviour: sampling methods. Behaviour 49:227-267

Anisko JJ, Christensen T, Buehler MG (1973) Effects of androgen on fighting behavior in male and female Mongolian gerbils (Meriones unguiculatus). Horm Behav 4:199-208

Appleby MC (1983) The probability of linearity in hierarchies. Anim Behav 31:600-608

Barroso FG, Alados CL, Boza J (2000) Social hierarchy in the domestic goat: effect on food habits and production. Appl Anim Behav Sci 69:35-53

Bateman AJ (1948) Intra-sexual selection in Drosophila. Heredity 2:349-368

Berger J (1986) Wild horses of the Great Basin. The University of Chicago Press, Chicago, pp 326

Berger J (1977) Organization systems and dominance in feral horses in the Grand Canyon. Behav Ecol Sociobiol 2:131146

Clutton Brock TH, Greenwood PJ, Powell RP (1976) Ranks and relationships in Highland ponies and Highland cows. Z Tierpsychol 41:202-216

Dabbs JM Jr Carr S, Frady R, Riad J (1995) Testosterone, crime, and misbehavior among 692 male prison inmates. Pers Individ Differ 18:627-633

David HA (1987) Ranking from unbalanced paired-comparison data. Biometrika 74:432-436

De Vries H (1995) An improved test of linearity in dominance hierarchies containing unknown or tied relationships. Anim Behav 50:1375-1389

De Vries H (1998) Finding a dominance order most consistent with a linear hierarchy: a new procedure and review. Anim Behav 55:827-843

De Vries H, Netto WJ, Hanegraaf PLH (1993) MATMAN: a program for the analysis of sociometric matrices and behavioral transmission matrices. Behaviour 125:157-175 
De Vries H, Stevens J, Vervaecke H (2006) Measuring and testing steepness of dominance hierarchies. Anim Behav 71:585-592

Drews C (1993) The concept and definition of dominance in animal behaviour. Behaviour 125:283-311

Ellis L (1995) Dominance and reproductive success among nonhuman animals: a cross-species comparison. Ethol Sociobiol 16:257-333

Feh C (1990) Long term paternity data in relation to different aspects of rank for Camargue stallions. Anim Behav 40:995996

Floody OR (1983) Hormones and aggression in female mammals. In: Svare BB (ed) Hormones and aggressive behavior. Plenum Press, New York, pp 39-89

Galimberti F, Fabiani A, Boitani L (2003) Socio-spatial levels in linearity analysis of dominance hierarchies: a case study on elephant seals. J Ethol 21:131-136

Gammell MP, De Vries H, Jennings DJ, Carlin CM, Hayden TJ (2003) David's score: a more appropriate dominance ranking method than Clutton-Brock et al.'s index. Anim Behav 66:601-605

Harcourt AH (1987) Dominance and fertility among female primates. J Zool Lond 213:471-487

Hemelrijk L, Gygax L (2004) Dominance styles, differences between the sexes and species. Interact Stud 5(1):131-146

Houpt KA, Wolski TR (1980) Stability of equine hierarchies and the prevention of dominance related aggression. Equine Vet J 12(1):15-18

Houpt KA, Keiper RP (1982) The position of the stallion in equine social organization. J Anim Sci 54:945-950

Houpt KA, Law K, Martinisi V (1978) Dominance hierarchies in domestic horses. Appl Anim Ethol 4:273-283

Jansen T, Forster P, Levine MA, Oelke H, Hurles M, Renfrew M, Weber J, Oelke K (2002) Mitochondrial DNA and the origins of the domestic horse. PNAS 99(16):10905-10910

Jensen P (2006) From behaviour to genes and back again. Appl Anim Behav Sci 97(1):3-15

Keiper RP (1986) Social structure. In: Crowell-Davis SL, Houpt KA (eds) Veterinary clinics of North America. Equine Pract 2(3):465-483

Keiper RP (1998) Social interactions of the Przewalski horse (Equus przewalskii Poliakov, 1881) herd at the Munich Zoo. Appl Anim Behav Sci 21(1-2):89-97

Keiper RP, Sambraus HH (1986) The stability of equine dominance hierarchies and the effect of kinship, proximity and foaling status on hierarchy rank. Appl Anim Behav Sci $16: 121-130$

Klingel H (1967) Soziale Organization und verhalten freilebender Steppenzebras. Z Tierpsych 24:580-624

Klimov VV (1988) Spatial-ethological organization of the herd of Przewalski horses (Equus przewalski) in Askania-Nova. Appl Anim Behav Sci 21(1-2):99-115

Koenig A (2002) Competition for resources and its behavioral consequences among female primates. Int $\mathrm{J}$ Primatol 23(4):759-782

Lehner PN (1996) Handbook of ethological methods, 2nd edn. Cambridge University Press, London, pp 672

Lott D, Galland JC (1987) Body mass as a factor influencing dominance status in American bison cows. J Mammal 68(3):683-685

Markerink M (2002) Koniks, wilde paarden in Nederland. Jan Van Arkel, Utrecht

Mazur A, Booth A (1998) Testosterone and dominance in men. Behav Brain Sci 21:353-397
McDonnell S (1992) Normal and abnormal sexual behavior. Vet Clin N Am 8(1):71-89

McDonnell S, Haviland JCS (1995) Agonistic ethogram of the equid bachelor band. Appl Anim Behav Sci 43:147-188

Motelica-Heino I, Edwards DA, Roffi J (1993) Intermale aggression in mice: does hour of castration after birth influence adult behaviour? Physiol Behav 53:1017-1019

Pluhacek J, Bartos L, Culik L (2006) High-ranking mares of captive plains zebra Equus burchelli have greater reproductive success than low-ranking mares. Appl Anim Behav Sci 99(1):315-329

Preuschoft S, Paul A, Kuester J (1998) Dominance styles of female and male barbary macaques (Macaca sylvanus). Behaviour 135:731-755

Pusey A, Williams J, Goodall J (1997) The influence of dominance rank on the reproductive success of female chimpanzees. Science 277:828-831

Reinhardt V, Reinhardt A (1975) Dynamics of social hierarchy in a dairy herd. Z Tierpsychol 38:315-323

Rutberg AT, Greenberg SA (1990) Dominance, aggression frequencies and modes of aggressive competition in feral pony mares. Anim Behav 40:322-331

Schilder M (1988) Dominance relationships between adult plains zebra stallions in semi-captivity. Behaviour 104:300319

Schilder M (1990) Social behaviour and social organization of a herd of plains zebra in a safari park. $\mathrm{PhD}$ Thesis, University of Utrecht, The Netherlands

Schilder MBH, Boer PL (1987) Ethological investigations on a herd of plains zebra in a safari park: time budgets, reproduction and food competition. Appl Anim Behav Sci $18: 45-56$

Sigurjónsdóttir H, van Dierendonck MC, Snorrason S, Thórhallsdottir AG (2003) Social relationships in a group of horses without a mature stallion. Behaviour 140:783-804

Smuts BB, Smuts RW (1993) Male aggression and sexual coercion of females in nonhuman primates and other mammals: evidence and theoretical implications. Adv Study Behav 22:1-63

Sterck EHM, Watts DP, Van Schaik CP (1997) The evolution of female social relationships in non-human primates. Behav Ecol Sociobiol 41:291-309

Swedell L (2001) Affiliation among females in wild hamadryas baboons (Papio hamadryas hamadryas). Int $\mathrm{J}$ Primatol 23(6):1205-1226

Trivers RL (1972) Parental investment and sexual selection. In: Campbell B (ed) Sexual selection and the descent of man. Aldine, Chicago, pp 136-179

Van Dierendonck M, De Vries H, Schilder M (1995) An analysis of dominance, its behavioral parameters and possible determinants in a herd of Icelandic horses. Neth J Zool 45(3-4):362-385

Van Schaik CP (1989) The ecology of social relationships among female primates. In: Standen V, Foley R (eds) Comparative socio-ecology of mammals and humans. Blackwell, Oxford

Van Hooff JARAM, Wensing JAB (1987) Dominance and its behavioral measures in a captive wolf pack. In: Frank HW (ed) Man and wolf. Junk, Dordrecht, pp 219-252

Vehrencamp S (1983) A model for the evolution of despotic versus egalitarian societies. Anim Behav 31:667-682

Vervaecke H, Roden C, De Vries H (2005) Dominance, fatness and fitness in female American bison (Bison bison). Anim Behav 70:763-770 
Von Holst D, Hutzelmeyer H, Kaetzke P, Khaschei M, Rödel HG, Schrutka H (2002) Social rank, fecundity and lifetime reproductive success in wild European rabits (Oryctolagus cuniculus). Behav Ecol Sociobiol 51:245-254

Waring G (2003) Horse behavior, 2nd edn. Noyes, Park Ridge, $375 \mathrm{pp}$
Wiepkema PR, Van Hooff JARAM (1977) Agressief gedrag: oorzaken en functies. Bohn, Scheltema \& Holkema, Utrecht, $373 \mathrm{pp}$

Whitsett JM (1975) The development of aggressive and marking behavior in intact and castrated male hamsters. Horm Behav 6:47-57 